\title{
KOMUNIKASI RINGKAS \\ PENGARUH PERBEDAAN VOLUME PERGANTIAN AIR TERHADAP LAJU SINTASAN DAN PERTUMBUHAN YUWANA SOTONG BULUH, Sepioteuthis lessoniana Lesson
}

\author{
Usman") M S Hamzah"), dan Taufik Ahmad"
}

\begin{abstract}
ABSTRAK
Penelitian ini bertujuan untuk mendapatkan persentase volume air yang optimal dalam pemeliharaan yuwana sotong buluh, Sepioteuthis lessoniana dengan sistem air mengalir. Wadah pemeliharaan berupa bak serat gelas sebanyak sembilan buah, diisi air laut masing-masing sebanyak $150 \mathrm{~L} /$ bak. Hewan uji berupa yuwana sotong buluh umur nol hari dengan bobot awa rata-rata $0,0250 \mathrm{~g}$ dan panjarig mantel awal rata-rata $5,0 \mathrm{~mm}$, ditebar ke dalam wadah pemeliharaan dengan kepadatan 100 ekor/bak. Selama pemeliharaan (30 hari), hewan uji diberi pakan hidup berupa jembret, Mesopodopsis sp. dan benih ikan nila merah secara ad-libitum Unit percobaan disusun berdasarkan rancangan acak lengkap yang terdiri atas tiga perlakuan persentase volume pergantian air yaitu 500\%, 1.000\%, dan $1.500 \%$ per hari, masing-masing terdiri atas tiga ulangan. Parameter yang diamati meliputi sintasan dan pertumbuhan yuwana sotong buluh serta kualitas air yang meliputi suhu, salinitas, oksigen terlarut, $\mathrm{pH}$, dan amonia. Perlakuan volume pergantian air $1.000 \%$ dan $1.500 \%$ menghasilkan sintasan yang lebih tinggi $(P<0,05)$ daripada volume pergantian air 500\%. Semua perlakuan menghasilkan pengaruh yang sama $(P>0,05)$ terhadap laju pertumbuhan harian hewan uji. Berdasarkan hasil penelitian ini dapat disimpulkan bahwa volume pergantian air sebanyak $1.000-1.500 \%$ per hari baik untuk pemeliharaan yuwana sotong buluh.
\end{abstract}

ABSTRACT: Effect of different water renewal volume on the survival and growth rates of bigfin squid, Sepioteuthis lessoniana, juvenile. By: Usman, M.S. Hamzah, and Taufik Ahmad.

The objective of this experiment was to find out the optimum percentage of water renewal on the survival and growth rate of bigfin squid, Sepioteuthis lessoniana, juvenile. The experiment was conducted in nine fiber glass tanks, each was filled with $150 \mathrm{~L}$ sea water. Juvenile (D-0) with an average weight of $0.0250 \mathrm{~g}$ and the average mantel length of $5.0 \mathrm{~mm}$ were reared at a stocking density of $100 \mathrm{ind}$.Itank. During the rearing period (30 days), the bigfin squid juvenile were given live feed such as mysid, Mesopodopsis sp. and red tilapia, Oreochromis niloticus, juvenile by ad-libitum. The experiment was arranged in a completely randomized design, consisted of three treatments of water renewal volumes namely 500\%, 1,000\%, and 1,500\% per day. Three replicate tanks were used per treatment. The variables measured were survival and growth rate of juvenile, temperature, salinity, dissolved oxygen, $\mathrm{pH}$, and amonia. The water renewal volume of 1,000\% and $1,500 \%$ per day resulted higher $(P<0.05)$ survival rate than that of $500 \%$. The amonia concentration was higher in low water renewal rate. It seemed that 1,000\%-1,500\% water renewal rate per day could maintain optimal water quality for bigfin squid juvenile rearing

KEYWORDS: water renewal, bigfin squid, juvenile, growth, survival rate

\section{PENDAHULUAN}

Sotong buluh, Sepioteuthis lessoniana Lesson, adalah sejenis cumi-cumi yang berukuran besar dengan distribusi di sekitar perairan pantai dan memiliki nilai ekonomis yang tinggi (Roper et al., 1984). Hingga saat ini produksi sotong buluh Indonesia masih mengandalkan hasil tangkapan dari alam yang kontinyuitasnya tidak terjamin. Penangkapan secara besar-besaran yang dilakukan oleh nelayan tanpa memperhatikan potensi sumber daya telah menyebabkan terjadinya kelebihan tangkap (over fishing) seperti yang terjadi di Selat Sape (Iskandar et al., 1992). Hal ini perlu diantisipasi sedini mungkin antara lain dengan upaya restocking dan pengembangan budi dayanya Dalam kegiatan budi daya laut di Indonesia, sotong buluh merupakan komoditas baru yang belum tersedia teknologinya baik aspek produksi benih maupun pembesarannya

\footnotetext{
Peneliti pada Balai Penelitian Perikanan Pantai, Maros
}

Peneliti pada Sumber Daya Laut P3O-LIPI Ambon 
Beberapa hasil percobaan pendahuluan yang dilakukan di Unit Penelitian Keramba Jaring Apung, Balai Penelitian Perikanan Pantai (Balitkanta) menunjukkan bahwa kendala utama yang dihadapi dalam upaya budi daya sotong buluh dalam keramba jaring apung adalah sintasan yuwana pada umur satu bulan masih sangat rendah (<7\%) (Ahmad \& Usman, 1996; Takdir 1996), akibat kualitas dan kuantitas pakan serta kondisi kualitas air yang belum optimal. Pada pemeliharaan yuwana sotong buluh dalam keramba jaring apung, goncangan air akibat ormbak dan arus air sangat mempengaruhi kemampuannya untuk menangkap makanannya. Selain itu kondisi yuwana sotong buluh sangat peka terhadap luka akibat gesekan dengan jaring saat diterpa gerakan air yang kuat, yang dapat mengakibatkan infeksi sekunder dan kematian

Pemeliharaan dalam bak-bak merupakan alternatif untuk meningkatkan laju sintasan yuwana sotong buluh. Tabiat makan yuwana sotong buluh menyukai makanan hidup (Bardach et al., 1972; Segawa, 1990; Lee et al., 1994) dan sering menyisakan sebagian makanan sehingga dapat meningkatkan kandungan senyawa beracun seperti amonia yang berdampak pada penurunan vitalitas, sintasan dan pertumbuhannya. Salah satu upaya yang dapat dilakukan untuk memperbaiki kualitas media pemeliharaan adalah dengan pergantian air secara mengalir.

\section{BAHAN DAN METODE}

Percobaan ini dilakukan di Unit Penelitian Keramba Jaring Apung, Balai Penelitian Perikanan Pantai yang berlokasi di perairan pantai Teluk Labuange, Kab. Barru, Sulawesi Selatan. Hewan uji berupa yuwana sotong buluh diperoleh dari hasil penetasan telur di keramba jaring apung. Yuwana tersebut dipelihara dalam sembilan bak serat gelas berkapasitas $200 \mathrm{~L}$ yang diisi air laut sebanyak $150 \mathrm{~L}$ dan dilengkapi dengan aerasi yang relatif sama untuk semua bak pemeliharaan. Setiap bak diisi yuwana sotong buluh yang baru menetas (D-0), memiliki bobot awal ratarata $0,0250 \mathrm{~g}$ dan panjang mantel awal rata-rata 5,0 mm dengan kepadatan 100 ekor/bak. Yuwana sotong buluh dipelihara selama 30 hari, dan selama pemeliharaan diberi pakan hidup berupa jembret, Mesopodopsis sp. dan burayak ikan nila merah secara ad-libitum. Rancangan percobaan yang digunakan adalah rancangan acak lengkap yang terdiri atas tiga perlakuan persentase volume air mengalir secara terus menerus yaitu 500\% (debit 31,25L/jam), 1.000\% $(62,50 \mathrm{~L} / \mathrm{jam})$, dan $1.500 \%(93,75 \mathrm{~L} / \mathrm{jam})$ dari volume bak pemeliharaan per hari dan masing-masing terdiri atas tiga ulangan. Penyiponan sisa pakan hanya dilakukan setiap pagi hari untuk menghindari frekuensi gangguan terhadap hewan uji
Parameter biologi yang diamati meliputi sintasan (Effendie, 1972) dan pertumbuhan harian yuwana sotong buluh (Segawa, 1990) dengan rumus:

$$
\begin{gathered}
\text { DGRW }=\frac{W / t}{t(W t+W o)} \times 100 \% \\
D G R L=\frac{L . t-L . O}{t(L t+L O) / 2} \times 100 \%
\end{gathered}
$$

dengan:

$$
\begin{aligned}
\text { DGRW = } & \text { Laju pertumbuhan harian bobot }(\%) \\
& \text { (Daily growth rate in body weight) }
\end{aligned}
$$

DGRL = Laju pertumbuhan harian panjang mantel

(Daily growth rate in mantel length)

$\mathrm{Wt}=$ Bobot pada waktu $-\mathrm{t}(\mathrm{g})$

Wo $=$ Bobot awal $(g)$

$\mathrm{Lt}=$ Panjang mantel pada waktu $-\mathrm{t}(\mathrm{mm})$

Lo = Panjang mantel awal $(\mathrm{mm})$

$\mathrm{t} \quad$ = Lama pemeliharaan (hari)

Parameter kualitas air yang meliputi suhu, salinitas, dan oksigen terlarut diamati setiap hari, sedang $\mathrm{pH}$ dan amonia diamati setiap lima hari. Data hasil pengamatan teritang sintasan dan pertumbuhan yuwana sotong buluh dianalisis ragam pada tingkat kepercayaan 95\%. Selanjutnya untuk mengetahui perbedaan pengaruh perlakuan diuji dengan beda nyata terkecil, sedangkan data kualitas air dianalisis secara deskriptif.

\section{HASIL DAN BAHASAN}

Sintasan dan pertumbuhan yuwana sotong buluh pada perlakuan perbedaan volume air secara mengalir, disajikan pada Tabel 1.

Pada Tabel 1 tersebut terlihat bahwa perlakuan pergantian volume air mengalir $1.000 \%$ dan $1.500 \%$ per hari menghasilkan sintasan yuwana sotong buluh lebih tinggi dibandingkan perlakuan pergantian volume air mengalir 500\% (PL 0.05). Sintasan pada perlakuan volume air mengalir $1.000 \%$ dan $1.500 \%$ tidak berbeda $(P>0,05)$.

Adanya perbedaan sintasan yang didapatkan, diduga berkaitan dengan pengaruh kualitas air media pemeliharaan akibat perbedaan volume air mengalir. Perlakuan volume air mengalir $1.000 \%$ dan $1.500 \%$ per hari cenderung memiliki kualitas air yang lebih baik dibandingkan dengan volume air mengalir 500\%, khususnya kandungan amonia (Tabel 2). Kandungan amonia yang didapatkan selama penelitian pada perlakuan volume air mengalir $1.000 \%$ dan $1.500 \%$ per hari lebih rendah dibandingkan dengan pada perlakuan volume air mengalir $500 \%$ per hari. Hal ini disebabkan karena tingkat pengenceran dan 
Tabel 1. Rata-rata sintasan dan pertumbuhan harian yuwana sotong buluh, Sepioteuthis lessoniana setelah 30 hari pemeliharaan dengan volume pergantian air yang berbeda

Table 1. The average survival and daily growth rate (DGR) of bigfin squid, Sepioteuthis lessoniana, juvenile at different water renewal rates for 30 days

\begin{tabular}{|c|c|c|c|c|}
\hline \multirow{2}{*}{$\begin{array}{l}\text { Variabel } \\
\text { (Variables) }\end{array}$} & \multirow{2}{*}{$\begin{array}{c}\text { Perairan } \\
\text { (Adjacent sea waters) }\end{array}$} & \multicolumn{3}{|c|}{ Volume pergantian air (Water exchange rates) } \\
\hline & & $500 \%$ & $1,000 \%$ & $1,500 \%$ \\
\hline $\begin{array}{l}\text { Suhu }\left({ }^{\circ} \mathrm{C}\right) \\
\text { Temperature }\left({ }^{\circ} \mathrm{C}\right)\end{array}$ & $29.0 \pm 1.6$ & $28.7 \pm 1.9$ & $28.7 \pm 1.2$ & $28.7 \pm 1.2$ \\
\hline $\begin{array}{l}\text { Salinitas (ppt) } \\
\text { Salinity (ppt) }\end{array}$ & $35 \pm 0.0$ & $35 \pm 0.0$ & $35 \pm 0.0$ & $35 \pm 0.0$ \\
\hline $\begin{array}{l}\mathrm{pH} \\
\text { Oksigen terlarut }(\mathrm{mg} / \mathrm{L}) \\
\text { Dissolved oxygen }(\mathrm{mg} / \mathrm{L})\end{array}$ & $\begin{array}{c}5.2 \pm 0.9 \\
7.75 \pm 0.30\end{array}$ & $\begin{aligned} 5.4 & \pm 0.5 \\
7.75 & \pm 0.27\end{aligned}$ & $\begin{aligned} 5.5 & \pm 0.6 \\
7.75 & \pm 0.30\end{aligned}$ & $\begin{array}{c}5.5 \pm 0.6 \\
7.75 \pm 0.30\end{array}$ \\
\hline Amonia (mg/L) & $0.0977 \pm 0.0822$ & $0.2142 \pm 0.0822$ & $0.1661 \pm 0.0311$ & $0.1490 \pm 0.0334$ \\
\hline
\end{tabular}

pembuangan amonia yang lebih tinggi pada perlakuan volume air mengalir $1.000 \%$ dan $1.500 \%$ per hari. Tabiat makan yuwana sotong buluh yang menyukai makanan hidup dengan cara makan mencabik-cabik serta menyisakan bagian kepala benih ikan nila merah yang relatif keras, menyebabkan penumpukan sisa pakan yang berakibat lanjut pada meningkatnya kandungan amonia dalam media pemeliharaan sampai di atas rata-rata 0,2 mg/L pada perlakuan volume air mengalir 500\% per hari. Wickins (1976) melaporkan bahwa kandungan amonia 0,2 mg/L sudah cukup menghambat pertumbuhan hewan akuatik pada umumnya. Selanjutnya Lee et al. (1994) merekomendasikan kandungan amonia sebesar < 0,1 mg/L. untuk pemeliharaan yuwana sotong buluh

Dampak konsentrasi amonia yang tinggi dalam pengamatan secara visual nampak pada tingkah laku makan yaitu yuwana sotong buluh pada volume air mengalir $500 \%$ cenderung memiliki nafsu makan yang lebih rendah dibandingkan dengan perlakuan volume air mengalir $1.000 \%$ dan $1.500 \%$. Kecenderungan ini diduga berkaitan dengan kandungan amonia yang mulai tinggi pada malam hari akibat penumpukan sisa pakan (penyifonan hanya dilakukan pagi hari untuk menghindari terjadinya gangguan dan stress pada hewan uji yang sangat peka terhadap gangguan dari luar), sehingga berdampak pada kematian yang lebih banyak pada malam hari khususnya menjelang pagi hari. Menurut Spotte (1979), amonia dalam bentuk molekul $\left(\mathrm{NH}_{3}\right)$ lebih beracun daripada ion $\mathrm{NH}_{4}^{+}$, dan daya racunnya akan meningkat pada $\mathrm{pH}$ dan suhu tinggi

Laju kematian yuwana sotong buluh yang tertinggi pada perlakuan volume pergantian air 500\% terjadi hingga 15 hari pertama, setelah itu pola kematiannya relatif sama dengan perlakuan volume pergantian air $1.000 \%$ dan $1.500 \%$. Hal ini diduga bahwa pada saat itu yuwana sotong buluh membutuhkan kualitas air yang betul-betul prima. Mutu kualitas air yang rendah dan tidak layak, selain secara langsung dapat meracuni yuwana sotong buluh juga menurunkan nafsu makan hingga akan menyebabkan terjadinya

Tabel2. Rata-rata nilai peubah kualitas air yang diamati pada pemeliharaan yuwana sotong buluh, Sepioteuthis lessoniana dengan volume air mengalir yang berbeda selama 30 hari

Table 2. Average values of water quality parameters of big fin squid, sepiotenthis lessoniana observed at different water renewal rates for 30 days

\begin{tabular}{|c|c|c|c|c|}
\hline \multirow{2}{*}{$\begin{array}{l}\text { Variabel } \\
\text { (Variables) }\end{array}$} & \multirow{2}{*}{$\begin{array}{c}\text { Perairan } \\
\text { (Adjacent sea waters) }\end{array}$} & \multicolumn{3}{|c|}{ Volume pergantian air (Water exchange rates) } \\
\hline & & $5,00 \%$ & $1,000 \%$ & $1,500 \%$ \\
\hline $\begin{array}{l}\text { Suhu }\left({ }^{\circ} \mathrm{C}\right) \\
\text { Temperature }\left({ }^{\circ} \mathrm{C}\right)\end{array}$ & $29.0 \pm 1.6$ & $28.7 \pm 1.9$ & $28.7 \pm 1.2$ & $28.7 \pm 1.2$ \\
\hline $\begin{array}{l}\text { Salinitas (ppt) } \\
\text { Salinity (ppt) }\end{array}$ & $35 \pm 0.0$ & $35 \pm 0.0$ & $35 \pm 0.0$ & $35 \pm 0.0$ \\
\hline $\mathrm{pH}$ & $5.2 \pm 0.9$ & $5.4 \pm 0.5$ & $5.5 \pm 0.6$ & $5.5 \pm 0.6$ \\
\hline $\begin{array}{l}\text { Oksigen terlarut }(\mathrm{mg} / \mathrm{L}) \\
\text { Dissolved oxygen }(\mathrm{mg} / \mathrm{L})\end{array}$ & $7.75 \pm 0.30$ & $7.75 \pm 0.27$ & $7.75 \pm 0.30$ & $7.75 \pm 0.30$ \\
\hline Amonia (Amonia) (mg/L) & $0.0977 \pm 0.0822$ & $0.2142 \pm 0.0822$ & $0.1661 \pm 0.0311$ & $0.1490 \pm 0.0334$ \\
\hline
\end{tabular}


kekurangan energi dan akhirnya terjadi kematian massal. Menurut Boyd \& Lichtkoppler (1979), untuk mempertinggi sintasan larva/benih, maka kondisi lingkungan perairan yang tepat harus tersedia.

Faktor kualitas air lainnya seperti suhu, salinitas, $\mathrm{pH}$, dan oksigen terlarut yang dimonitoring selama percobaan relatif seragam di antara perlakuan, dan secara umum masih cukup layak bagi kehidupan yuwana sotong buluh karena masih relatif sama dengan kualitas perairan sekitarnya yang merupakan daerah penyebaran sotong buluh

\section{KESIMPULAN}

Pergantian air $1.000 \%$ dan $1.500 \%$ lebih baik dibandingkan 500\% terhadap sintasan tetapi tidak ada pengaruh perbedaan volume pergantian air tersebut terhadap laju pertumbuhan dan panjang mantel yuwana sotong buluh hingga umur 30 hari. Kandungan amonia pada kedua perlakuan volume pergantian air mengalir $1.000 \%$ dan $1.500 \%$ per hari lebih rendah $(0,1661 \pm 0,0311 \mathrm{mg} / \mathrm{L}$ dan 0,1490 $\pm 0,334 \mathrm{mg} / \mathrm{L})$ dari pada perlakuan volume pergantian air mengalir $500 \%$ per hari $(0,2124 \pm 0,0822 \mathrm{mg} / \mathrm{L})$.

\section{DAFTAR PUSTAKA}

Ahmad, T. dan Usman. 1996. Bigfin squid culture: The Indonesian experience, In Proceeding of the Seventh Workshop of the Tropical Marine Mollusc Programme (TMMP) Java, Indonesia, 11-12 November 1996. p.285-287

Bardach, J.E., J.H. Ryther, and W.O. McLarney. 1972. Aquaculture: The Farming and Husbandry of Freshwater and Marine Organisms. John Wiley and Sons Inc., New York. 868 pp
Boyd, C.E. and F. Lichtkopler. 1979. Water Quality Management in Pond Fish Culture, International Center for Aquaculture, Auburn University Alabama, Research and Development. $30 \mathrm{pp}$

Effendi. M.I. 1979. Metode Biologi Perikanan. Yayasan Agromedia, Bogor. 112 p

Iskandar, B., B. Sumiono, dan B. Basuki. 1992. Dugaan potensi, analisis usaha, dan prospek pengembangan sumber daya cumi-cumi (Loligo spp.) di Selat Sape, Nusa Tenggara Barat. Jurnal Penelitian Perikanan Laut. Jakarta, (66):17-28.

Lee, G.P., P.E. Turk, W.T. Yang, and R.T. Hanlon. 1994. Biological characteristic and biomedical applications of the squid, Sepioteuthis lessoniana cultured through multiple generations. Biol. Bull., (186):328$341 p$.

Roper, C.F.E., M.J. Sweeney, and C.F. Nauen. 1984. Cephalopods of the World. Species Cataloque of Interest to Fisheries, FAO Fish, synop., 3(125): 277 p.

Segawa, S. 1990. Food consumption, food conversion and growth rates of the oval squid, Sepioteuthis lessoniana by laboratory experiments. Nippon Suisan Gakkasihi, 56(2):217-222p

Spotte, S. 1979. Fish and Invertebrate Culture: Water Management in Closed System. John Wiley and Sons, New York. 179 pp.

Takdir, M. 1996. Studi Penetasan Telur, Pemeliharaan Larva, dan Biologi Reproduksi Cumi-Cumi (Sepioteuthis lessoniana). Tesis Pascasarjana, Universitas Hasanddin, Ujung Pandang. $60 \mathrm{p}$

Wickins. J.F. 1976. Prawn Biology and Culture Oceanography and Marine Biology. Annual Review, (14):435-507p. 